\title{
Cellular Changes of the Corneal Epithelium and Stroma in Herpes Simplex Keratitis
}

\section{Citation}

Hamrah, Pedram, Afsun Sahin, Mohammad H. Dastjerdi, Bashar M. Shahatit, Hasan A. Bayhan, Reza Dana, and Deborah Pavan-Langston. 2012. "Cellular Changes of the Corneal Epithelium and Stroma in Herpes Simplex Keratitis." Ophthalmology 119 (9) (September): 1791-1797. doi:10.1016/j.ophtha.2012.03.005.

\section{Published Version}

10.1016/j.ophtha.2012.03.005

\section{Permanent link}

http://nrs.harvard.edu/urn-3:HUL.InstRepos:34428279

\section{Terms of Use}

This article was downloaded from Harvard University's DASH repository, and is made available under the terms and conditions applicable to Other Posted Material, as set forth at http:// nrs.harvard.edu/urn-3:HUL.InstRepos:dash.current.terms-of-use\#LAA

\section{Share Your Story}

The Harvard community has made this article openly available.

Please share how this access benefits you. Submit a story.

\section{Accessibility}




\title{
Cellular Changes of the Corneal Epithelium and Stroma in Herpes Simplex Keratitis: An In Vivo Confocal Microscopy Study
}

\author{
Pedram Hamrah, MD1, Afsun Sahin, MD'1,2, Mohammad H. Dastjerdi, MD1, Bashar M. \\ Shahatit, MD ${ }^{1}$, Hasan A. Bayhan, MD ${ }^{1}$, Reza Dana, MD, MPH ${ }^{1}$, and Deborah Pavan- \\ Langston, MD \\ ${ }^{1}$ Massachusetts Eye \& Ear Infirmary, Ocular Surface Imaging Center, Cornea Service, \\ Department of Ophthalmology, Harvard Medical School, Boston, Massachusetts, United States \\ ${ }^{2}$ Department of Ophthalmology, Eskisehir Osmangazi University Medical School, Eskisehir, \\ Turkey
}

\begin{abstract}
Purpose-To analyze the morphology of corneal epithelial cells and keratocytes by in vivo confocal microscopy (IVCM) in patients with herpes simplex keratitis (HSK) as associated with corneal innervation.

Design-Prospective, cross-sectional, controlled, single-center study.

Participants-Thirty-one eyes with the diagnosis HSK and their contralateral clinically unaffected eyes were studied and compared with normal controls $(n=15)$.

Methods-In vivo confocal microscopy (Confoscan 4; Nidek Technologies, Gamagori, Japan) and corneal esthesiometry (Cochet-Bonnet; Luneau Ophthalmologie, Chartres, France) of the central cornea were performed bilaterally in all patients and controls. Patients were grouped into normal $(>5.5 \mathrm{~cm})$, mild $(>2.5-5.5 \mathrm{~cm})$, and severe $(<2.5 \mathrm{~cm})$ loss of sensation.
\end{abstract}

Main Outcome Measures-Changes in morphology and density of the superficial and basal epithelial cells, as well as stromal keratocytes were assessed by two masked observers. Changes were correlated to corneal sensation, number of nerves, and total length of nerves.

Results-There was a significant and gradual decrease in the density of superficial epithelial cells in HSK eyes, with $852.50 \pm 24.4$ cells $/ \mathrm{mm}^{2}$ in eyes with severe sensation loss and $2435.23 \pm 224.3$ cells $/ \mathrm{mm}^{2}$ in control eyes $(\mathrm{p}=0.008)$. Superficial epithelial cell size was 2.5 -fold larger in HSK eyes $\left(835.3 \mu \mathrm{m}^{2}\right)$ as compared to contralateral or normal eyes $\left(407.4 \mu \mathrm{m}^{2} ; \mathrm{p}=\right.$ $0.003)$. A significant number of hyperreflective desquamating superficial epithelial cells were present in HSK eyes with normal (6.4\%), mild (29.1\%) and severe (52.2\%) loss of sensation, but were absent in controls. The density of basal epithelial cells, anterior keratocytes, and posterior keratocytes did not show statistical significance between patients and controls. Changes in

(C) 2012 American Academy of Ophthalmology, Inc. Published by Elsevier Inc. All rights reserved

Correspondence to: Pedram Hamrah, MD, Cornea Service, Massachusetts Eye \& Ear Infirmary, Harvard Medical School, 243 Charles Street, Boston, MA 02114, pedram_hamrah@meei.harvard.edu.

Publisher's Disclaimer: This is a PDF file of an unedited manuscript that has been accepted for publication. As a service to our customers we are providing this early version of the manuscript. The manuscript will undergo copyediting, typesetting, and review of the resulting proof before it is published in its final citable form. Please note that during the production process errors may be discovered which could affect the content, and all legal disclaimers that apply to the journal pertain.

Conflict of Interest: The authors have no financial/conflicting interests to disclose.

This work was presented in part at the Association of Research in Vision and Ophthalmology in Ft. Lauderdale, Florida, April 2009, and at the Ocular Microbiology and Immunology Group in Atlanta, Georgia, November 2008. 
superficial epithelial cell density and morphology correlated strongly with total nerve length, number, and corneal sensation. Scans of contralateral eyes did not show any significant epithelial or stromal changes as compared to controls.

Conclusions-IVCM reveals profound HSK-induced changes in the superficial epithelium, as demonstrated by increase in cell size, decrease in cell density, and squamous metaplasia. We demonstrate that these changes strongly correlate with changes in corneal innervation.

\section{INTRODUCTION}

Herpes simplex virus (HSV) is the most common infectious cause of unilateral blindness in the developed world. ${ }^{1-3}$ The incidence of new cases of HSV keratitis (HSK) is estimated to be around 20,000 cases per year and the total number of cases per year is estimated to be around 48,000 in the United States with a prevalence of 400,000. ${ }^{4-6}$ Cytopathic effects of HSV are usually followed by an inflammatory response, which can seriously damage all corneal layers. ${ }^{7}$ The spectrum of ocular disease caused by the HSV is broad and underscored by a latent presence of the virus in the ganglionic neurons or the cornea. ${ }^{8,9}$ The large majority of HSK seen in clinical practice is due to recurrences caused by shedding of reactivated virus. ${ }^{9}, 10$ HSK typically presents as epithelial keratitis, necrotizing stromal and immune keratitis, endotheliitis, or neurotrophic keratopathy (NTK). ${ }^{11,}{ }^{12}$ NTK may be manifested clinically by persistent corneal epithelial defects, decreased visual acuity, stromal opacification, corneal neovascularization, and stromal melts. NTK is thought to result from loss of corneal sensation due to denervation, damaged epithelial basement membrane, stromal inflammation, and toxicity from topical medication.

Until recently, slit-lamp examination has been the gold standard for detecting epithelial defects, stromal edema and infiltration, keratic precipitates, and iritis due to HSV. Recently, in vivo confocal microscopy (IVCM) has become an increasingly popular non-invasive device to image the cornea at the cellular and microstructural level in healthy as well as diseased corneas. ${ }^{13-18}$ Several studies have demonstrated the feasibility of this technology and have analyzed the corneal epithelium in ocular rosacea, ${ }^{19}$ Sjogren's syndrome, ${ }^{19}, 20$ meibomian gland dysfunction, ${ }^{19}$ dry eye, ${ }^{21,22}$ Stevens-Johnson syndrome, ${ }^{23}$ and keratitis. ${ }^{15}, 18,24,25$ More recently, our group has demonstrated that patients with unilateral HSK demonstrated bilateral subbasal corneal nerve alteration by IVCM. ${ }^{17}$ Further, the subbasal corneal nerve changes correlated strongly with loss of corneal sensation in the affected eyes of these patients. However, the consequences of altered sensory nerve function on other corneal layers remain unknown. Given the fact that regulation of epithelial cells by nerves has previously been shown in animal models, ${ }^{26,27}$ in the current study, we aimed to study how corneal nerve and sensation loss in patients with HSK affect the corneal epithelium and stroma in these patients. We hypothesized that corneal nerve loss would lead to loss of epithelial cells and keratocytes in patients with HSK. The morphology and density of corneal epithelial cells and keratocytes was thus analyzed by IVCM in patients with HSK and was correlated to corneal innervation in this group.

\section{PATIENTS AND METHODS}

Our institutional review board/ethics committee approved this prospective, cross-sectional study, which was conducted in a controlled, single-masked fashion. Written informed consent was obtained form all subjects after a detailed explanation of the nature of the study. This study was Health Insurance Portability and Accountability Act (HIPAA) compliant and adhered to the tenets of the Declaration of Helsinki.

All subjects were recruited from the Cornea Service of the Department of Ophthalmology of the Massachusetts Eye \& Ear Infirmary, Boston, Massachusetts, between 2006 and 2008. 
Subjects with a history of ocular trauma, ocular surgery, contact lens use, or diabetes were excluded from the study. All patients and normal subjects were examined by slit-lamp biomicroscopy. The diagnosis of HSK was made according to epithelial dendritic lesions characteristic of epithelial HSV keratitis. All patients had epithelial herpetic keratitis with no stromal involvement. All patients have had epithelial herpetic keratitis with no stromal involvement. Seven patients had acute HSK (herpetic epithelial infection within the last 10 weeks), and 24 had chronic HSK (infection has occurred in a period longer than 10 weeks). The chronic HSK group included patients that were followed after one or more acute episodes of epithelial HSV keratitis. Patients were also divided according to the clinical location of the herpetic lesion, in central $(n=20)$ and peripheral $(n=11)$ herpetic keratitis.

Prior to recruitment into the study, all patients underwent a baseline complete ophthalmologic examination including visual acuity measurement, anterior segment evaluation with a slit-lamp biomicroscope, fundus examination, and IOP measurement by non-contact applanation tonometry. Central corneal sensation was measured bilaterally with a Cochet-Bonnet esthesiometer (Luneau Ophthalmologie, Chartres, France). The esthesiometer was always used in the unaffected eye first. This test mechanically stimulates corneal nerves by pressing a retractable 6 -cm length monofilament nylon thread of $0.12-\mathrm{mm}$ diameter against the anterior corneal surface, shortening in steps of $1.0 \mathrm{~cm}$ if a positive response is not obtained. If a positive response is obtained, the thread is advanced by $0.5 \mathrm{~cm}$. The longest filament length resulting in a positive response was considered the corneal sensitivity threshold, which was verified twice.

A total of 31 eyes of 28 patients with a diagnosis of HSK ( 3 bilateral), as well as the contralateral, clinically unaffected eyes, were included in this study. Fifteen eyes of 10 normal volunteers comprised the control group. HSV keratitis patients were grouped into normal $(>5.5 \mathrm{~cm})$, mild $(>2.5-\square 5.5 \mathrm{~cm})$, and severe $(<2.5 \mathrm{~cm})$ loss of corneal sensation, according to the corneal sensitivity threshold measurements, and results were correlated to confocal microscopical findings. Further, patients were divided according to the clinical location of the herpetic lesion, in central and peripheral herpetic keratitis. No fluorescein was used prior to IVCM during the visit. All subjects underwent bilateral examination of the central cornea with a slit-scanning confocal microscope (Confoscan 4; Nidek Technologies, Gamagori, Japan). All patients were given a code at the time of scanning (a combination of numbers/letters), which was used on the Confoscan instead of their names. The key to patient identity/diagnosis was saved in a separate file. Thus, during image selection, the observers (P.H. and M.H.D.) were masked to patient name, diagnosis and severity at the time of image selection. The microscope was equipped with a 40x/0.75 Zeiss Acroplan numerical aperture immersion objective lens. After topical $0.5 \%$ proparacaine eyedrop (Alcaine; Alcon, Fort Worth, TX) was installed in both eyes, a drop of $0.3 \%$ hypromellose (GenTeal gel; Novartis, East Hanover, NJ) was applied to the objective lens as an optical coupling medium. The lens was then manually advanced until the gel contacted the central surface of the cornea. Full-thickness confocal scans were acquired at a speed of 25 frames per second, obtaining 350 images per scan every $7 \mu \mathrm{m}$. A second scan was obtained for the anterior cornea, obtaining sections every $3 \mu \mathrm{m}$. Each image represented a coronal section of $460 \square \times 345 \mu \mathrm{m}$, with a minimum axial step of $1 \mu \mathrm{m}$, magnification of X500, and lateral resolution of $1 \mu \mathrm{m} / \mathrm{pixel}$. A total of 4 to 8 scans were obtained for each cornea by the same experienced operator $(\mathrm{PH})$ in all subjects, depending on full-thickness or anterior scan mode.

Three representative images per layer were selected for analysis for each eye and averaged. Layers included in the analysis were superficial epithelial layer, basal epithelial layer, subbasal corneal nerves, anterior stromal keratocytes, and posterior stromal keratocytes. Two masked observers evaluated the confocal images in regards to morphology and density for each layer. Cell counts were performed manually by Confoscan 4 NAVIS analysis 
software. This was achieved by marking each clearly defined cell or nucleus in a predefined rectangular frame using the full frame size on the computer screen. All counts were performed independently by two masked experienced examiners to determine superficial and basal epithelial cell density, as well as anterior and posterior keratocyte density. Superficial epithelial cells become highly reflective before desquamation. ${ }^{28}$ To assess epithelial damage, percentage of highly-reflective superficial epithelial cells was calculated by dividing highly-reflective cells per frame by total number of superficial epithelial cells per frame and multiplying by 100 . For epithelial cell size, operators defined the borders of superficial epithelial cells, with Confoscan Software NAVIS calculating epithelial cell area. The areas superficial epithelial cells were averaged per frame. Cellular changes of the epithelium and stroma were correlated to corneal sensation, number of nerves, and total length of nerves/image as described before. ${ }^{29}$ Briefly, nerve density was assessed by measuring the total length of the nerve fibers in micrometers per frame $\left(158,700 \mu \mathrm{m}^{2}\right)$. Main nerve trunks were defined as the total number of main nerves in 1 image. Nerve branching was defined as the total number of nerve branches in 1 image. The number of total nerves measured was defined as the number of all nerves, including main nerve trunks and branches, per image. Statistical analysis was performed by Student's $T$-test, analysis of variance (ANOVA), and Pearson correlation coefficient. $P$-values less than 0.05 were considered statistically significant. Analyses were performed with SAS software version 9.2 (SAS Institute Inc., Cary, NC).

\section{RESULTS}

Thirty-one eyes of 28 patients with HSK and 25 contralateral unaffected eyes were included for analysis in the study and were compared with 15 eyes of 15 normal volunteers. Three patients $(10.7 \%)$ in the study group had bilateral clinical HSV keratitis. Patient characteristics of the HSK and control groups are shown in Table 1. In order to correlate corneal sensation to IVCM findings, all eyes with HSK were subcategorized into 3 groups based on central corneal sensation, and into central (20 eyes) and peripheral (11 eyes) location of the herpetic lesion. Eyes were classified as normal sensation, mild sensation loss, and severe sensation loss as described in the methods section. The correlation of corneal sensation loss to IVCM parameters of superficial epithelium, basal epithelium, anterior and posterior keratocytes for all groups is presented in Table 2. Representative IVCM images for all layers analyzed for patients with HSK and controls are shown in Figure 1.

There was a significant and gradual decrease in the density of superficial epithelial cells in HSK eyes, with $1628.33 \pm 348.12$ cells $/ \mathrm{mm}^{2}$ in HSK eyes with normal sensation, $1382.5 \pm$ 73.55 cells $/ \mathrm{mm}^{2}$ in HSK eyes with mild sensation loss, and $852.50 \pm 24.4$ cells $/ \mathrm{mm}^{2}$ in eyes with severe sensation loss as compared to $2435.23 \pm 224.3$ cells $/ \mathrm{mm}^{2}$ in control eyes ( $\mathrm{p}=$ 0.008) (Fig 2A). The changes in superficial epithelial cell density were not statistically significant, between the other normal and mild sensation loss HSK groups and controls, or between contralateral eyes and controls. Stratification of HSK patients based on central versus peripheral location of HSK lesions, demonstrated no statistically significant changes in the affected or contralateral eyes, for all parameters. There was a gradual increase in superficial epithelial cell size with loss of corneal sensation in HSK eyes. Superficial epithelial cell size was 2.5-fold larger in HSK eyes with severe loss of sensation (835.3 \pm $50.30 \mu \mathrm{m}^{2} ;$ ) as compared to contralateral or normal eyes $\left(407.4 \pm 47.2 \mu \mathrm{m}^{2} ; \mathrm{P}=0.003\right)$ (Fig. 1B). The IVCM scans in mild and severe sensation loss revealed a significant increase in mean superficial epithelial cell size ( $p=0.046, p=0.001$ respectively), as compared with the normal control group, while HSK with normal sensation did not demonstrate statistically significant changes from normal controls. $(\mathrm{p}=0.3)$ 
There were several other gradual morphological changes noted in superficial epithelial cells in patients with HSK with loss of corneal sensation. While there was minimal reflectivity of cell nucleoli in controls or contralateral eyes, eyes with HSK consistently demonstrated increased reflectivity of superficial epithelial cell nucleoli. In addition, patients with mild sensation loss and particularly patients with severe sensation loss demonstrated a hyporeflective ring around the hyperreflective cell nucleoli. Moreover, HSK eyes with normal sensation demonstrated bright cell borders and increased cell hyperreflectivity, which was more pronounced in patients with mild and severe loss of sensation. A significant number of hyperreflective desquamating superficial epithelial cells were present in HSK eyes with normal sensation $(6.4 \% \pm 16.23 \%, \mathrm{p}=0.09)$, mild $(29.1 \% \pm 12.33 \%, \mathrm{p}=0.002)$ and severe $(52.2 \% \pm 13.78 \%, \mathrm{p}=0.0003)$ loss of sensation, but were absent in controls or contralateral eyes (Fig. 3). Although a decreased density in basal epithelial cells and anterior keratocytes was noted, the density of basal epithelial cells, anterior keratocytes, and posterior keratocytes did not show statistical significance between patients, contralateral eyes and controls, despite the demonstration of a bilateral loss of subbasal nerve plexus as we have described previously. ${ }^{15}$ When we compared the clinical location of the herpetic lesion analyzing epithelial cell and keratocytes alterations between the central and peripheral herpetic lesions, no statistical difference was observed in the patients. Finally, in order to confirm the appropriate sample size or our study, we performed power calculations, which demonstrated a power of $>91 \%$ for all statistically significant variables of the superficial epithelium.

\section{DISCUSSION}

The corneal epithelium serves as a barrier and helps maintain the corneal transparency. Any damage to corneal epithelium caused by physical or microbial, including viral insults, results in stromal swelling, the activation of stromal fibroblasts, and inflammatory cell infiltration, leading to the loss of corneal transparency. ${ }^{30}$ The assessment of corneal epithelial cell health, has until recently, only been possible by slit-lamp biomicroscopy. The use of IVCM now sheds light to our understanding of corneal physiology and homeostasis, ${ }^{15}$ and allows systematic studies of corneal epithelial cell morphologic features and density in normal subjects and in patients. This methodology is non-invasive, precise, reproducible, rapid, and has a relatively low inter-observer variability, as compared to slit-lamp examination.

The current IVCM study is to the best of our knowledge, the first study analyzing corneal epithelial cell morphology and density in patients with HSK, correlating IVCM findings to corneal sensation and clinical history of HSK. We found that changes in superficial epithelial cell density and morphology correlated strongly with corneal sensation. This finding also supports our hypothesis that impaired neural integrity leads to epithelial morphological changes. Previously, Rosenberg et al. ${ }^{25}$ reported pathological corneal changes by IVCM in 16 HSV keratitis patients. Although they did not find any changes in subbasal nerve plexus, they showed that epithelial cells were enlarged, although the results where not quantified. In a more recent study by Alomar et al. ${ }^{13}$, the authors performed histopathological correlation with IVCM findings in corneal intraepithelial neoplasia patients. They concluded that prominent large nuclei and size changes in epithelial cells have been seen in conditions such as rapid cellular turnover and regenerative atypia as during wound healing. Further, in a study by Benitez del Castillo et al. ${ }^{31}$ it was shown that density of superficial epithelial cells as well as subbasal nerve plexus decreased significantly in dry eye patients. In yet another study, IVCM showed hyperreflectivity of the nucleus and a decrease in the nucleocytoplasmic ratio in the superficial epithelial cells in StevensJohnson syndrome. ${ }^{23}$ They attributed these changes to dry eye and subbasal nerve loss. More recently, Roszkowska et al. ${ }^{32}$ showed severe superficial epithelial changes by IVCM in Salzmann nodular degeneration of the cornea by IVCM. They observed enlarged 
squamous cells with prominent nuclei and bright margins in the superficial layer of the central corneal epithelium. In dry eye patients, it has been shown that the mean superficial and intermediate epithelial cell densities were significantly lower than in normal subjects, while no changes in basal epithelial cell density had been noted. ${ }^{22}$ These findings had been speculated to be due to decreased subbasal nerve density, a common finding in dry eye patients. Similarly, Harrison and co-workers ${ }^{33}$ demonstrated no changes in the basal epithelial cell density in a heterogeneous set of corneal diseases. Further, in a study performed on Sjogren's syndrome patients, Villani and co-workers ${ }^{20}$ showed a significant decrease in superficial epithelial cell density. Moreover, Hovakimyan et al. ${ }^{34}$ demonstrated hyperreflectivity of superficial epithelial cells two weeks after collagen cross-linking. Finally, hyperreflective corneal epithelial cells were also found in pterygium cases. ${ }^{35}$ The limits between the pterygium and the adjacent cornea were irregular with infiltration of hyperreflective cells within the cornea. Fuchs patches were observed as islets of hyperreflective polygonal cells in front of the pterygium head with blurred limits. Given the strong correlation of superficial epithelial cell parameters with corneal sensation and innervation, our findings are suggestive that not only loss of sensation, but also changes in the superficial epithelium, may be a direct result of the diminished subbasal nerve plexus in HSK patients. Because neurotrophic keratopathy initially lacks signs and symptoms, and may progress to corneal perforation, quantification of epithelial cell density and morphology by IVCM can be a valuable tool for monitoring patients with HSK or any other patient populations with epithelial disease, potentially predicting the risk for neurotrophic keratopathy or clinically apparent epithelial disease.

In the current study, we also compared diseased eyes with unaffected contralateral eyes and normal controls. While we have recently shown that the subbasal corneal nerve plexus is affected bilaterally in apparently unilateral HSK, ${ }^{15}$ the current study demonstrates that the contralateral epithelium is not affected. While superficial epithelial cell morphology and density in HSK eyes was significantly altered with decreased cell density, increased cell size and increase in hyperreflectivity, these changes were not present in contralateral eyes of these patients. These data are consistent with the findings of normal corneal sensation in the contralateral eyes, despite reduced nerve density..$^{15} \mathrm{We}$ had demonstrated that corneal nerve density higher than $1064 \mu \mathrm{m} /$ frame is sufficient for a patient to have near normal sensation. Thus, it seems that this nerve density is sufficient to maintain epithelial integrity as well. These findings also explain why the previous study by Rosenberg et al. ${ }^{25}$ did not find a difference in subbasal nerve and epithelial changes between the affected and unaffected contralateral eyes.

A limitation of our study is that we were only able to evaluate the central corneal epithelium and that the findings cannot necessarily be extrapolated to the peripheral cornea. In addition, the Cochet-Bonnet esthesiometer only measures mechanical nociceptors. ${ }^{36}$ Third, there are also thermal receptors in the cornea, which we cannot measure with the Cochet-Bonnet esthesiometer, which has a limited scale. ${ }^{37}$ Gallar et al. ${ }^{37}$ elegantly demonstrated that HSV keratitis disrupts mechanical nociceptors as well as heat and cold thermoreceptors.

Sensory nerves play an important role in maintenance of corneal epithelial integrity. ${ }^{38}$ It is known that neuropeptides influence corneal cell proliferation in vitro ${ }^{26}$ and corneal epithelial cell mitosis has been shown to be altered in denervated rats. ${ }^{39}$ Partial or complete loss of corneal sensation or denervation, leads to impaired corneal epithelial homeostasis due to the lack of these neuropeptides, including substance P, nerve growth factor (NGF), vasoactive intestinal peptide, and glucagon like peptides. ${ }^{27,38,40-43}$ Epithelial homeostasis is physiologically controlled by a tight regulation of apoptosis and proliferation, the balance between which is perturbed in NTK. In addition, it has recently been shown that denervation has a deleterious effect on the apoptosis of corneal epithelial cells,${ }^{44}$ and induces a reduction 
of epithelial cell mitosis. ${ }^{39}$ Further, it was reported that two salient corneal epithelial functions (permeability and wound healing) are significantly altered by sensory denervation. ${ }^{38}$ After sensory denervation, an inflammatory response ensues due to loss of epithelial homeostasis. ${ }^{38,45}$ Superficial epithelial cells start losing their tight junctions and attach weakly to each other. ${ }^{46}$ The inflammation enriched with proinflammatory cytokines, such as interleukin (IL)-1 and IL-6, leads to the activation of keratocytes, which synthesize NGF and other nerve growth factors. ${ }^{47}$ These activated keratocytes then stimulate epithelial cells to migrate and proliferate, leading to changes in their shape and size due to modifications in actin cytoskeleton. ${ }^{38,45,48-50}$ Thus, it is conceivable that enlarged superficial epithelial cells as seen by IVCM could be representative of cells in a particular state of metabolic activation induced by proinflammatory cytokines or as a result of apoptosis of neighboring cells. Moreover, the reduced number of superficial epithelial cells and the increased hyperreflectivity may be due to extensive apoptotic response widely seen in denervated corneas. ${ }^{44}$ On the other hand, a proliferative response is triggered to balance apoptosis in denervated corneas. This response may explain why we did not see a decrease in the basal epithelial layer. It is thus likely that decreased neural innervation in cornea may lead to changes in neuropeptide levels, resulting in epithelial cell changes detected by IVCM in our HSK patients.

In conclusion, IVCM enables a direct and reproducible comparison between epithelial cell morphology and corneal sensation. The detection of subclinical epithelial cell changes could provide an objective quantitative evaluation of epithelial cell health, before clinical findings present. Given that new treatment options are being investigated for NTK, IVCM may allow objective evaluation of treatment response through quantification of cellular changes in the cornea.

\section{Acknowledgments}

We would like to thank Dr. Andrea Cruzat for assistance in the preparation of the manuscript.

Financial Support: NIH K08-EY020575 (PH), NIH K24-EY019098 (RD), Falk Medical Research Foundation (PH), Research to Prevent Blindness Career Development Award (PH) Johnstone Research Foundation (DPL), Stevens Fund (DPL).

The funding organizations had no role in the design or conduct of this research.

\section{References}

1. Dawson CR, Togni B. Herpes simplex eye infections: clinical manifestations, pathogenesis and management. Surv Ophthalmol. 1976; 21:121-35. [PubMed: 988644]

2. Pepose J, Keadle T, Morrison L. Ocular herpes simplex: changing epidemiology, emerging disease patterns, and the potential of vaccine prevention and therapy. Am J Ophthalmol. 2006; 141:547-57. [PubMed: 16490506]

3. Liesegang TJ. Herpes simplex virus epidemiology and ocular importance. Cornea. 2001; 20:1-13. [PubMed: 11188989]

4. Liesegang TJ. A community study of ocular herpes simplex. Curr Eye Res. 1991; 10(suppl):111-5. [PubMed: 1864087]

5. Liesegang TJ. Epidemiology of ocular herpes simplex: natural history in Rochester, Minn, 1950 through 1982. Arch Ophthalmol. 1989; 107:1160-5. [PubMed: 2757546]

6. Liesegang TJ, Melton LJ III, Daly PJ, Ilstrup DM. Epidemiology of ocular herpes simplex: incidence in Rochester, Minn, 1950 through 1982. Arch Ophthalmol. 1989; 107:1155-9. [PubMed: 2787981]

7. Sundmaher, R. Color Atlas of Herpetic Eye Diseases: A Practical Guide to Clinical Management. Springer; Berlin: 2009. p. 5-112. 
8. Farooq AV, Shukla D. Corneal latency and transmission of herpes simplex virus-1. Future Virol. 2011; 6:101-8. [PubMed: 21436960]

9. Hill JM, Clement C. Herpes simplex virus type 1 DNA in human corneas: what are the virological and clinical implications? J Infect Dis. 2009; 200:1-4. [PubMed: 19476431]

10. Remeijer L, Duan R, van Dun JM, et al. Prevalence and clinical consequences of herpes simplex virus type 1 DNA in human cornea tissues. J Infect Dis. 2009; 200:11-9. [PubMed: 19476433]

11. Liesegang TJ. Classification of herpes simplex virus keratitis and anterior uveitis. Cornea. 1999; 18:127-43. [PubMed: 10090358]

12. Holland EJ, Schwartz GS. Classification of herpes simplex virus keratitis. Cornea. 1999; 18:14454. [PubMed: 10090359]

13. Alomar TS, Nubile M, Lowe J, Dua HS. Corneal intraepithelial neoplasia: in vivo confocal microscopic study with histopathologic correlation. Am J Ophthalmol. 2011; 151:238-47. [PubMed: 21168809]

14. Efron N, Perez-Gomez I, Mutalib HA, Hollingsworth J. Confocal microscopy of the normal human cornea. Cont Lens Anterior Eye. 2001; 24:16-24. [PubMed: 16303449]

15. Hamrah P, Cruzat A, Dastjerdi MH, et al. Corneal sensation and subbasal nerve alterations in patients with herpes simplex keratitis: an in vivo confocal microscopy study. Ophthalmology. 2010; 117:1930-6. [PubMed: 20810171]

16. Hillenaar T, Weenen C, Wubbels RJ, Remeijer L. Endothelial involvement in herpes simplex virus keratitis: an in vivo confocal microscopy study. Ophthalmology. 2009; 116:2077-86. [PubMed: 19744733]

17. Hollingsworth J, Perez-Gomez I, Mutalib HA, Efron N. A population study of the normal cornea using an in vivo, slit-scanning confocal microscope. Optom Vis Sci. 2001; 78:706-11. [PubMed: 11700964]

18. Martone G, Alegente M, Balestrazzi A, et al. In vivo confocal microscopy in bilateral herpetic keratitis: a case report. Eur J Ophthalmol. 2008; 18:994-7. [PubMed: 18988174]

19. De Nicola R, Labbe A, Amar N, et al. In vivo confocal microscopy and ocular surface diseases: anatomical-clinical correlations [in French]. J Fr Ophtalmol. 2005; 28:691-8. [PubMed: $16208218]$

20. Villani E, Galimberti D, Viola F, et al. The cornea in Sjogren's syndrome: an in vivo confocal study. Invest Ophthalmol Vis Sci. 2007; 48:2017-22. [PubMed: 17460255]

21. Zhang X, Chen Q, Chen W, et al. Tear dynamics and corneal confocal microscopy of subjects with mild self-reported office dry eye. Ophthalmology. 2011; 118:902-7. [PubMed: 21146227]

22. Erdelyi B, Kraak R, Zhivov A, et al. In vivo confocal laser scanning microscopy of the cornea in dry eye. Graefes Arch Clin Exp Ophthalmol. 2007; 245:39-44. [PubMed: 16874525]

23. Vera LS, Gueudry J, Delcampe A, et al. In vivo confocal microscopic evaluation of corneal changes in chronic Stevens-Johnson syndrome and toxic epidermal necrolysis. Cornea. 2009; 28:401-7. [PubMed: 19411958]

24. Gabison EE, Alfonsi N, Doan S, et al. Archipelago keratitis: a clinical variant of recurrent herpetic keratitis? Ophthalmology. 2007; 114:2000-5. [PubMed: 17418418]

25. Rosenberg ME, Tervo TM, Muller LJ, et al. In vivo confocal microscopy after herpes keratitis. Cornea. 2002; 21:265-9. [PubMed: 11917174]

26. Garcia-Hirschfeld J, Lopez-Briones LG, Belmonte C. Neurotrophic influences on corneal epithelial cells. Exp Eye Res. 1994; 59:597-605. [PubMed: 9492761]

27. Klyce SD, Beuerman RW, Crosson CE. Alteration of corneal epithelial ion transport by sympathectomy. Invest Ophthalmol Vis Sci. 1985; 26:434-42. [PubMed: 2858455]

28. Wiegand W, Thaer AA, Kroll P, et al. Optical sectioning of the cornea with a new confocal in vivo slit-scanning videomicroscope. Ophthalmology. 1995; 102:568-75. [PubMed: 7724174]

29. Calvillo MP, McLaren JW, Hodge DO, Bourne WM. Corneal reinnervation after LASIK: prospective 3-year longitudinal study. Invest Ophthalmol Vis Sci. 2004; 45:3991-6. [PubMed: 15505047]

30. Suzuki K, Saito J, Yanai R, et al. Cell-matrix and cell-cell interactions during corneal epithelial wound healing. Prog Retin Eye Res. 2003; 22:113-33. [PubMed: 12604055] 
31. Benitez del Castillo JM, Wasfy MA, Fernandez C, Garcia-Sanchez J. An in vivo confocal masked study on corneal epithelium and subbasal nerves in patients with dry eye. Invest Ophthalmol Vis Sci. 2004; 45:3030-5. [PubMed: 15326117]

32. Roszkowska AM, Aragona P, Spinella R, et al. Morphological and confocal investigation on Salzmann nodular degeneration of the cornea. Invest Ophthalmol Vis Sci. 2011; 52:5910-9. [PubMed: 21705683]

33. Harrison DA, Joos C, Ambrosio R Jr. Morphology of corneal basal epithelial cells by in vivo slitscanning confocal microscopy. Cornea. 2003; 22:246-8. [PubMed: 12658092]

34. Hovakimyan M, Guthoff R, Reichard M, et al. In vivo confocal laser-scanning microscopy to characterize wound repair in rabbit corneas after collagen cross-linking. Clin Experiment Ophthalmol. 2011; 39:899-909. [PubMed: 21718406]

35. Labbe A, Gheck L, Iordanidou V, et al. An in vivo confocal microscopy and impression cytology evaluation of pterygium activity. Cornea. 2010; 29:392-9. [PubMed: 20164747]

36. Patel DV, Tavakoli M, Craig JP, et al. Corneal sensitivity and slit scanning in vivo confocal microscopy of the subbasal nerve plexus of the normal central and peripheral human cornea. Cornea. 2009; 28:735-40. [PubMed: 19574916]

37. Gallar J, Tervo TM, Neira W, et al. Selective changes in human corneal sensation associated with herpes simplex virus keratitis. Invest Ophthalmol Vis Sci. 2010; 51:4516-22. [PubMed: 20375335]

38. Beuerman RW, Schimmelpfennig B. Sensory denervation of the rabbit cornea affects epithelial properties. Exp Neurol. 1980; 69:196-201. [PubMed: 7389846]

39. Sigelman S, Friedenwald JS. Mitotic and wound-healing activities of the corneal epithelium: effect of sensory denervation. AMA Arch Ophthalmol. 1954; 52:46-57. [PubMed: 13170864]

40. Nakamura M, Chikama T, Nishida T. Synergistic effect with Phe-Gly-Leu-Met-NH2 of the Cterminal of substance $\mathrm{P}$ and insulin-like growth factor-1 on epithelial wound healing of rabbit cornea. Br J Pharmacol. 1999; 127:489-97. [PubMed: 10385250]

41. Bonini S, Lambiase A, Rama P, et al. Topical treatment with nerve growth factor for neurotrophic keratitis. Ophthalmology. 2000; 107:1347-51. [PubMed: 10889110]

42. Lambiase A, Manni L, Bonini S, et al. Nerve growth factor promotes corneal healing: structural, biochemical, and molecular analyses of rat and human corneas. Invest Ophthalmol Vis Sci. 2000; 41:1063-9. [PubMed: 10752942]

43. Drucker DJ. Glucagon-like peptides: regulators of cell proliferation, differentiation, and apoptosis. Mol Endocrinol. 2003; 17:161-71. [PubMed: 12554744]

44. Ferrari G, Chauhan SK, Ueno H, et al. A novel mouse model for neurotrophic keratopathy: trigeminal nerve stereotactic electrolysis through the brain. Invest Ophthalmol Vis Sci. 2011; 52:2532-9. [PubMed: 21071731]

45. Lu L, Reinach PS, Kao WW. Corneal epithelial wound healing. Exp Biol Med (Maywood). 2001; 226:653-64. [PubMed: 11444101]

46. Araki K, Ohashi Y, Kinoshita S, et al. Epithelial wound healing in the denervated cornea. Curr Eye Res. 1994; 13:203-11. [PubMed: 8194368]

47. Tuominen IS, Konttinen YT, Vesaluoma MH, et al. Corneal innervation and morphology in primary Sjogren's syndrome. Invest Ophthalmol Vis Sci. 2003; 44:2545-9. [PubMed: 12766055]

48. Beuerman RW, Thompson HW. Molecular and cellular responses of the corneal epithelium to wound healing. Acta Ophthalmol Suppl. 1992; 202:7-12. [PubMed: 1378989]

49. Crosson CE, Klyce SD, Beuerman RW. Epithelial wound closure in the rabbit cornea: a biphasic process. Invest Ophthalmol Vis Sci. 1986; 27:464-73. [PubMed: 3957565]

50. Beuerman RW, Schimmelpfennig B. Sensory denervation of the rabbit cornea affects epithelial properties. Exp Neurol. 1980; 69:196-201. [PubMed: 7389846] 

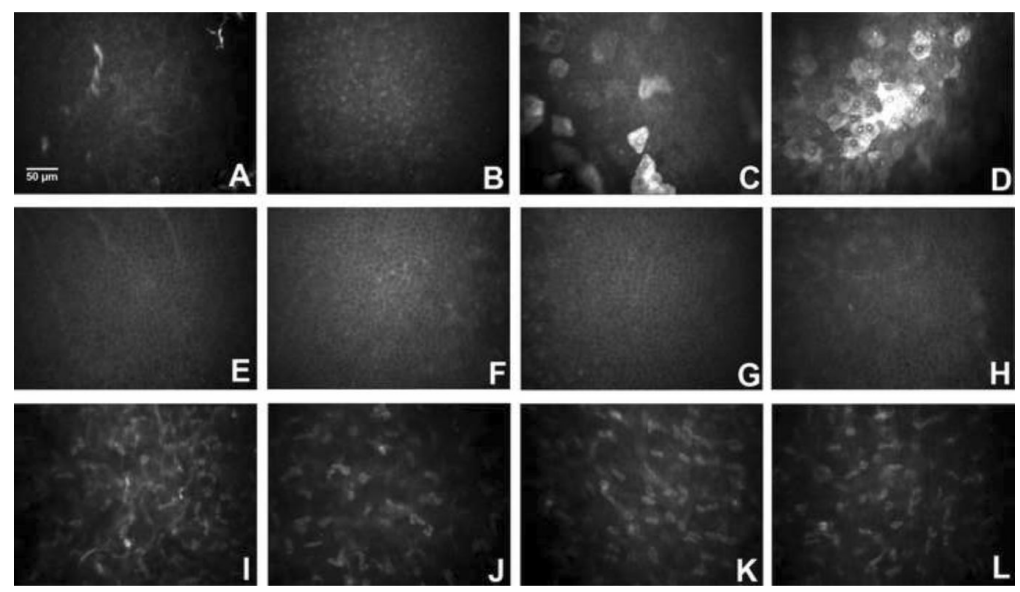

Figure 1.

In vivo confocal microscopy images at the level of the corneal epithelium and stroma in patients with Herpes Simplex keratitis (HSK). A-D) Superficial epithelium A) Normal cornea. B) HSK, normal sensation; No increase in cell size; No decrease in density; prominent nucleoli and bright cell borders are present. C) HSK, mild sensation loss; Increase in cell size and decrease in density; further increase in hyperreflectivity. D) HSK, severe sensation loss; Very large cells; Lower cell density; Highly reflective cells. E-H) Basal epithelium. E) Normal cornea. F) HSK, normal sensation. G) HSK, mild sensation loss. H) HSK, severe seneation loss. -H) Basal Epithelium; No significant changes with loss of sensation. I) Normal cornea, anterior stroma. J) HSK, severe sensation loss, anterior stroma. K) Normal cornea, posterior stroma. L) HSK, severe loss of sensation, posterior stroma. 


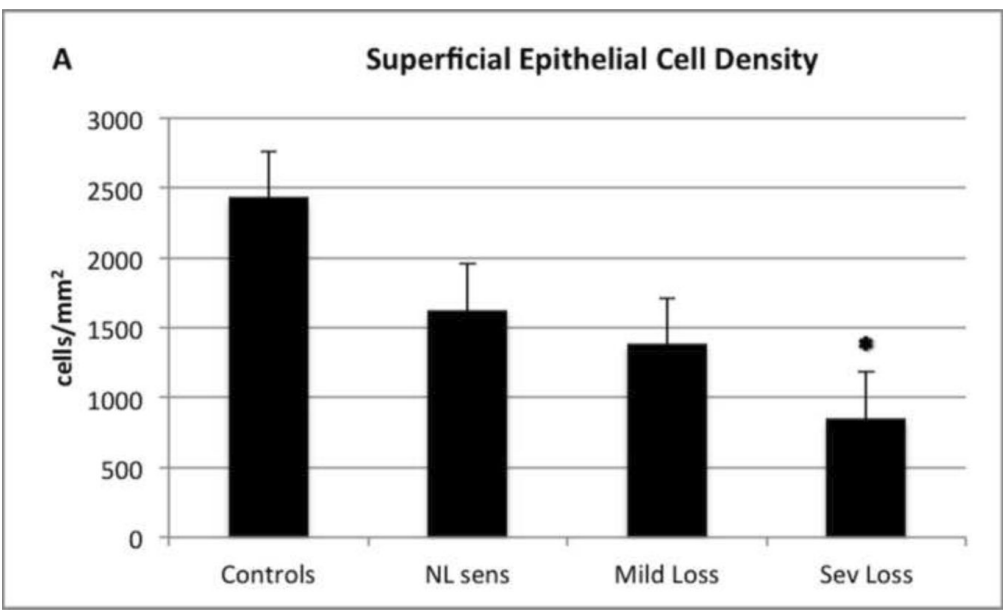

B Superficial Epithelial cell size

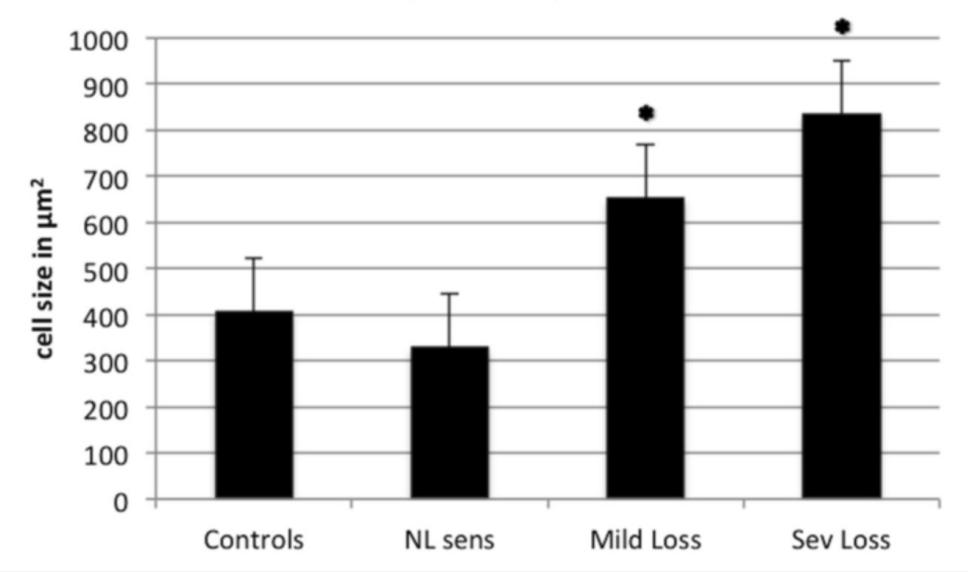

Figure 2.

Superficial epithelial cell density (A) and superficial epithelial cell size (B) in herpes simplex keratitis (HSK) according to corneal sensation loss classification. Error bars represents standard error from the mean. ${ }^{*} \mathrm{p}<0.05$ compared to control group. Statistical analysis by ANOVA: (analysis of variance between groups). As the corneal sensation decreases in patients with HSK, the superficial epithelial cell density decreases and superficial epithelial cell size increases significantly. NL:Normal, Sens:Sensation, Sev:Severe. 


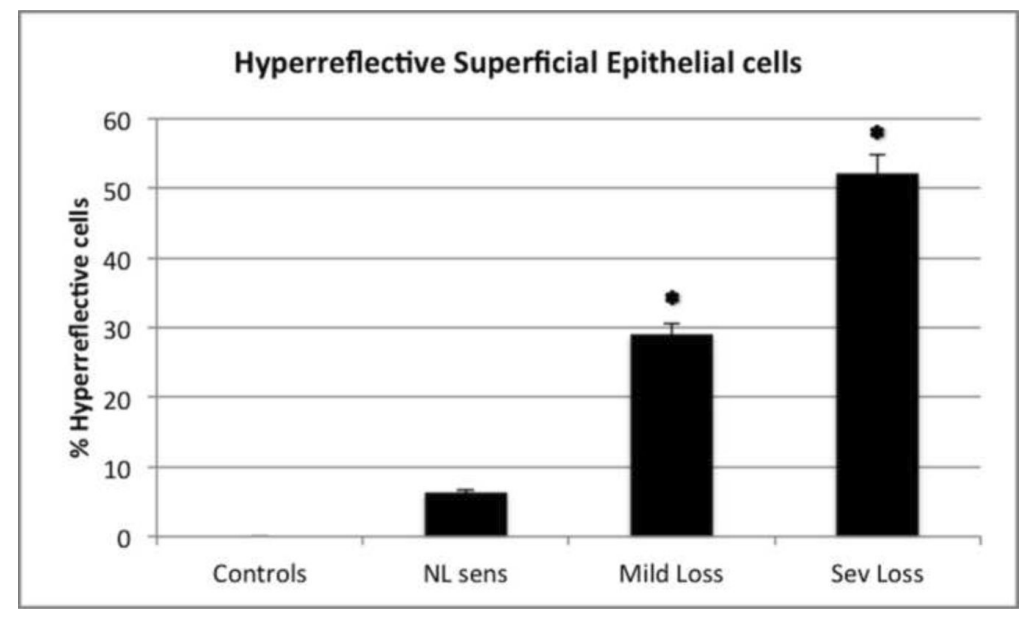

Figure 3.

Hyperreflective desquamating superficial epithelial cells in herpes simplex keratitis (HSK) according to corneal sensation loss classification. Error bars represents standard error from the mean. ${ }^{*} \mathrm{p}<0.05$ compared to control group. Statistical analysis by ANOVA: (analysis of variance between groups). As the corneal sensation decreases the number of hyperreflective superficial epithelial cells increases significantly. NL:Normal, Sens:Sensation, Sev:Severe. 
Table 1

Demographic Data of Normal Controls and Patients with Herpes Simplex Virus Keratitis

\begin{tabular}{|l|l|l|}
\hline & Controls & Herpes Simplex Keratitis \\
\hline No of patients & 15 & $28(25$ unilateral disease, 3 bilateral disease $)$ \\
\hline Age (mean \pm SD; years) & $59 \pm 17$ & $62.1 \pm 19.1$ \\
\hline Gender (male/female) & $8 / 7$ & $8 / 20$ \\
\hline Corneal Sensation (mean $\pm \mathrm{SD} ; \mathrm{cm})$ & $6.0 \pm 0$ & $3.3 \pm 1.9$ \\
\hline Disease duration (mean $\pm \mathrm{SD} ;$ years) & - & $14.8 \pm 15.1$ \\
\hline No. of episodes (mean $\pm \mathrm{SD} ; \mathrm{n})$ & - & $3.0 \pm 2.1$ \\
\hline Clinical location of herpetic lesions & - & 20 central / 11 peripheral \\
\hline
\end{tabular}

SD: Standard deviation 


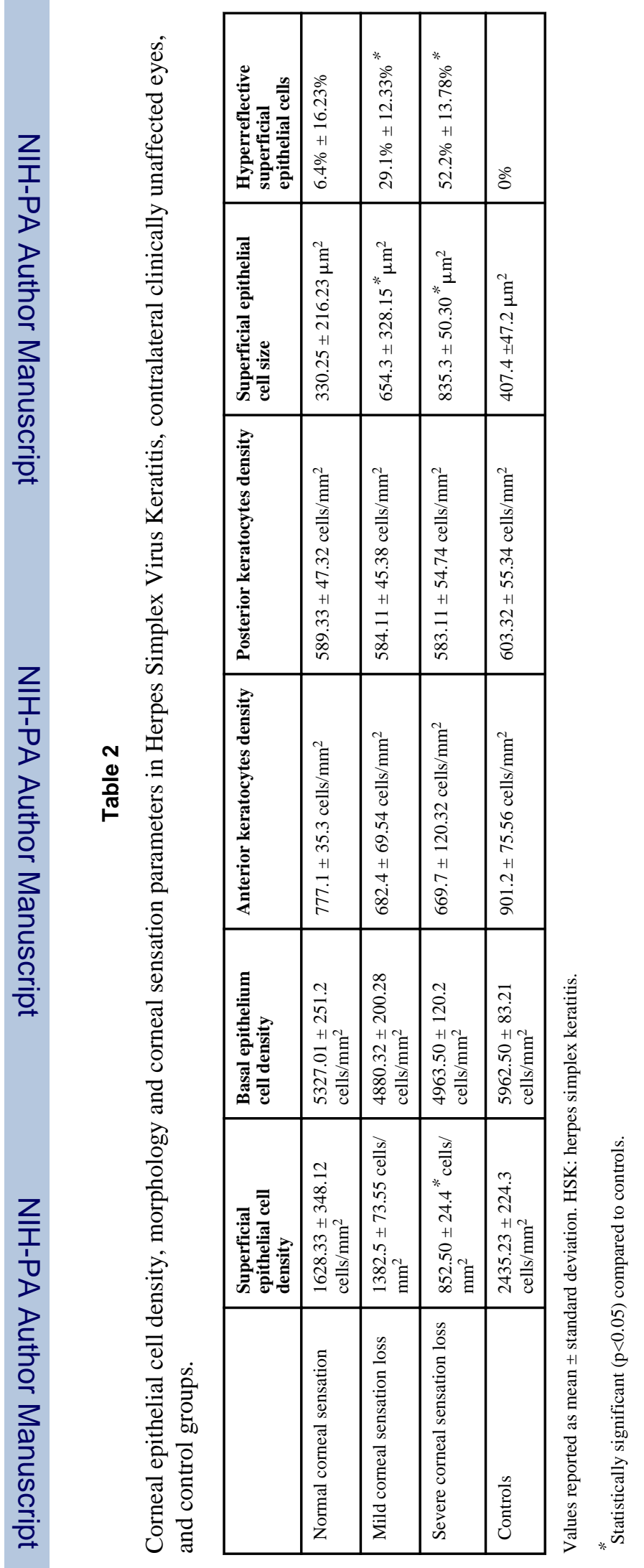

Ophthalmology. Author manuscript; available in PMC 2013 September 01. 